\title{
Study on Lightweight Concrete- Review
}

\author{
${ }^{1}$ Rishab Meena, ${ }^{2}$ Sumit Sharma, ${ }^{3}$ Anuj Sharma, ${ }^{4}$ Mukesh Kumar \\ ${ }^{1}$ B.Tech students, Department of Civil Engineering, HIET College, Ghaziabad, U.P, India \\ ${ }^{2}$ Professor, Department of Civil Engineering, HIET College, Ghaziabad, U.P, India \\ ${ }^{3}$ Professor, Department Civil Engineering, HIET College, Ghaziabad, U.P, India \\ ${ }^{4}$ H.O.D., Department of Civil Engineering, HIET College, Ghaziabad, U.P, India
}

\begin{abstract}
It is lighter than the conventional concrete. The use of lightweight concrete has been widely spread across countries. This type of concrete contains expanded light weight aggregates which increase the volume of the mixture. This paper illustrates the several applications and advantages of the lcw. Moreover it portrays the methods of production and further properties. It had been beneficial for the construction purposes.
\end{abstract}

\section{INTRODUCTION}

Light weight concrete (LWC) is an amazing human invention which is used in several fields of construction. It has numerous numbers of applications which are immensely important like frames and floors, curtain walls, shell roofs, folded plates, bridges, off-shore oil platforms, and precast. The strength of LWC is 25 to $35 \%$ light as compared to normal one.

Altogether the concrete are of three types and they are subdivided on the basis of weights which are heavy concrete, normal weight and light weight concrete. The compositions are as follows

Heavy-3200 kg/m to $4000 \mathrm{~kg} / \mathrm{m}$

Normal-2400 kg/m to $2600 \mathrm{~kg} / \mathrm{m}$

Light $-2000 \mathrm{~kg} / \mathrm{m}$.

\subsection{Historical review -}

Light weight concrete is not a latest invention done by humans. It has been used evidently from ancient time, it can be traced to as early as 3,000 BC, when Mohenjo-Daro and Harappa civilizations.

Moreover it was also used by the Romans and magnificent ancient structures still exists, like St. Sofia Cathedral or Hagia Sofia, in Istanbul, in Turkey.

Furthermore, there are several examples which show the use of LWC primarily in the construction for example the Roman temple, Pantheon, which was erected in the years A.D. 118 to 128 and to add on the prestigious aqueduct, Pont du Gard, built ca. A.D. 14; and the great Roman amphitheatre, Coliseum, built between A.D. 70 and 82 .

One the contrary, the use of light weight concrete declined after the fall of Roman Empire and people started using different material and adopted new measures for construction.

\section{PRODUCTION PROCESS AND PROPERTIES}

There are various processes in which we can produce the LWC. The first and foremost way to make LWC is produced by eliminating the fine aggregates from the mix completely which is called no-fines concrete. The second most common method of producing this concrete is 'Aerated Concrete', sometimes also referred as foamed, gas or cellular concrete. The method of processing it quiet different as it is formed by indulgence of bubble voids into the concrete it helps to form a cellular structure.

The third type of classification consists of Lightweight Aggregate Concrete' (LWAC). This has the specific gravity less as compared to normal concrete which is 2.6. These are the most often type of concrete used in the system. They are mainly used for construction process because of the characteristics they offer. There are various properties desired in materials used as lightweight aggregates which are as follows -

1) Particle shape and surface texture:

As we have studied earlier that there are various methods to produce the LWC and different producers are preferring various method for production of this concrete hence the shape and the surface texture is exceptionally different.

2) Bulk specific gravity: it's the second property in which defines that because of the cellular structure of lightweight aggregate the specific gravity of normal concrete is more as compared to lightweight aggregates.

3) Unit Weight: In the case of weight the LWC is low as compared to all the other kind of concrete that is because of the cellular structure of lightweight aggregate.

4) Strength of lightweight aggregates: according to the experimental the strength of LWC depends on the method of production.

5) Moisture content and absorption:

Due to their molecular structure they are capable of absorbing more water as compared to the other form of aggregates. Lightweight mixture generally Imbibe from 5 to 20 percent by weight of arid compound.

Moreover all the other properties of LWC such as Elastic properties, compressive and tensile strength, time dependent properties, durability, fire resistance depend upon the type of aggregates. There are various difficulties which are faced during the application of LWC such as the normal mix design procedure to the light- weight concrete and due to the rapid absorption quality.

\section{APPLICATIONS OF LWC}

There are numerous numbers of applications of LWC which are being undertaken for the production purpose. Three main the aggregates that fall under 'Low Density Concrete' have low unit weight $(800 \mathrm{~kg} / \mathrm{m} 3)$. Sometimes they are desired as the fill in concrete due to the compressive strength which is equal to 7.0 to $17.0 \mathrm{mpa}$ which is also referred as moderate strength concrete.

In out native place it is used as the masonry blocks and due to the light weight of the blocks it is exceptionally easy for the labor to carry the blocks and it helps to easily transfer them to different places and complete the circuit at 
incredible speed which is beneficial for the plant, as the work is being done at high speeds.

\section{ADVANTAGES OF LWC}

The first and the foremost advantage of the lightweight aggregate is that they are well suited for the seismic design due to reduce the dead load of a concrete structure. Moreover it works exceptionally well during the natural calamities for example during earthquakes they work ideally dour to the light weight.

There are various advantages over the normal concrete such as higher strength/weight ratio, better tensile strain capacity, lower coefficient of thermal expansion, and superior heat and sound insulation characteristics due to air voids.

\section{LITERATURE REVIEW}

- Yasar et.al. - This experiment consist of various parts such as he performed a study on the design of structural lightweight concrete (SLWC) made with basaltic pumice (scoria) as aggregate and fly ash and hence it provides an evident advantage over the reduction of weight. The properties of fresh concrete including density, and slump and due to these many beneficial reasons it is more compressive and greener.

- H. Al-Khaiat and M.N. Haque -He worked on the curing the physical properties and the early strength. And moreover lightweight concrete using Lytag LWA with a slump of about $100 \mathrm{~mm}$, fresh unit weight of $1800 \mathrm{~kg} / \mathrm{m} 3$ and 28 day cube compressive strength. Furthermore the test shows the compressive strengths of SLWC seems to be less sensitive to lack of curing than the NWC.

- Khandaker M. Anwar Hossain - he carried out an investigation on volcanic pumice. Test was conducted after $0 \%$ to $25 \%$ of cement by weight and on concrete by replacing $0 \%$ to $100 \%$ of coarse aggregate by volume.

The VPC properties were differentiated on the basis of volcanic pumice aggregate (VPA) and various tests were conducted such as workability, strength, drying shrinkage, surface absorption and water permeability.

- T. Parhizkar et.al. - Exhibited experiments on the properties of volcanic pumice lightweight aggregates concretes. During the conclusion of the mainly lightweight coarse with natural fine aggregates concrete and lightweight coarse and fine aggregates concrete. The study concludes various results such as tensile strength and drying shrinkage show that these lightweight concretes meet the requirements.

- P.C.Taylor- currently professor at Wuhan University of Technology has quoted various results such as mineral admixtures affect the physical and mechanical properties of High Strength Structural Light Concrete.amd moreover concluded that further addition of fly ashes improves the compressive strength and splitting tensile strength of HSSLC and furthermore Addition of silica fume enhances the compressive strength about $25 \%$.
- Banthia, N. and Trottier,J. - fabricated research on concrete reinforced with deformed steel fibers and this results in enhancing the compressive strength.

- Compione, G., et.al- suggested that the presence of fiber in the concrete is exceptional and helps to reduce the decay in the field of strains and moreover suggested that brittle nature can be overcome by ordinary confinement of transverse reinforcement.

\section{CONCLUSION-}

In the upcoming years light weight cement has gained popularity due to its economic characteristics. Moreover, since lightweight aggregate can be used in cast in place, load bearing and non-load bearing structures, it is an exceptional alternative for the normal (heavy weight) aggregate which is being used in Indian markets. There is an immense need in Indian market for the LWC and new mandatory norms should be applied in the market for there more usage. They are extremely helpful in various purposes.

\section{REFERENCES}

[1] Banthia, N. and Trottier, J. (1994)

[2] Balguru, P. and Foden, A., (1999)

[3] Bhaskar Desai and A. Sathyam, February 20141 ISSN 22503153

[4] Compione, G., La Mendola L. and Miraglia, Nov. 1999, 1- 17-26

[5] D. Sari, A.G. Pasamehmetoglu. (2005)

[6] Ergul Yasar, Cengiz Duran Atis, Alaettin Kilic, Hasan Gulsen. (2003)

[7] Guide for Structural Lightweight Aggregate Concrete ACI213R87 (Reapproved 1999)

[8] H. Al-Khaiat and M.N. Haque

[9] P.C.Taylor (2008)

[10] T. Parhizkar (2012)

[11] Khandaker M. Anwar Hossain. (2004) 